\title{
Partner Relations and Work Stress Modulating Health Issues
}

\author{
Ann-Christine Andersson Arntén ${ }^{1 *}$, Bengt Jansson ${ }^{2}$ and Trevor Archer ${ }^{2}$ \\ ${ }^{1}$ Department of National Operations, Assessment Functions, Stockholm, Sweden \\ ${ }^{2}$ Department of Psychology, University of Gothenburg, Göteborg, Sweden
}

\begin{abstract}
Two hundred and twelve participants, 135 male and 77 female, derived from several different occupations, responded to questionnaires based upon several self-report instruments including the Subjective Stress Experience Questionnaire (psychological and somatic), the Stress and Energy Scale, the Hospital Anxiety and Depression (HAD) Scale, the Job Stress Survey (JSS), Partnership Relations Quality (PRQ) Test, and the Positive and Negative Affect Scale (PANAS). It was found that self-reported high levels of work stress (the JSS "High work stress" group) induced more anxiety, stress (SE), psychological and somatic subjective stress, and negative affect than selfreported low levels of work stress (the JSS "Low work stress" group), with intermediate levels of work stress (the JSS "Medium work stress" group) in between. Self-reported high levels of partnership relations quality (the "High PRQ" group) was associated with less depression, anxiety, stress (SE) and negative affect than self-reported low levels of partnership relations quality (the "High PRQ" group), with intermediate levels (the "Medium PRQ" group) in between. Regression analysis indicated that depressive, anxiety, stress (SE), psychological stress and somatic stress were each significantly predicted by work stress (JSS), whereas partnership relations quality was counter-predictive for depression, anxiety, stress (SE) and psychological stress. Female participants expressed higher levels of stress and energy (SE), anxiety and psychological stress (SSE) than the male participants. The present findings tentatively suggest the health-promoting advantages of positive partnership, and/or familial, relations in counteracting the illhealth accruing from various types of general stress (SE, psychological and somatic) and the particular stresses of work occupation.
\end{abstract}

Keywords: Stress; Partnership relations; Work stress; Anxiety; Depression; Gender; Interaction

\section{Introduction}

A currently-held belief is that marriage promotes health and that single individuals are at greater risk for illheath than married/ common-law couples. This belief is supported by research showing that marital/partnership relations, under some conditions, may generate positive health effects for both men and women [1,2]. On the other hand, Whisman and Bruce [3] found that co-habiting partnership dissatisfaction was associated with almost $70 \%$ of disorders assessed by the Ontario Health Survey Mental Health Supplement (including those connected with anxiety and depression). Concomitant studies focussed on work-related stress present a similar association of stress in the work environment implicated in physical and psychological health issues [4$11]$.

Involvement in a partner relationship (PR) has been found to exert a strong influence upon how individuals experience the global aspects of life satisfaction [12]. Maslow [13] postulated that each human being possesses the need for 'loving' and 'to be loved'. The capacity to develop a loving relationship, characterised by intimity and respect, remains a basic prerequisite for individual satisfaction, according to Maslow [14]. This contention is supported by Forrester [15] who indicates that what most strongly predicts individual life satisfaction is involvement in a PR based upon love. Thus, individuals involved in a well-functioning partner relationship report higher levels of life satisfaction and lower levels of neuroticism [16]. Nevertheless, it must be considered too that not only partnership but the quality of the relationship is important. Accordingly, PR quality may function as buffer against stressful events [17], through (i) protecting against risks associated with social isolation $[18,19]$; (ii) exerting an indirect influence on health via increased socioeconomic resources [20]; (iii) optimising healthrelated behaviours that thereby reduce health-destructive behaviours [21,22]. Conversely, negative PR and/or marital distress, with physical and psychological influences, may affect both physiological and psychobiological stress reactions [17,23,24]. For example, Barnett et al. [25] found an association between marital quality and stress markers whereby individuals with marital problems estimated higher stress levels and markers whereby individuals with marital problems estimated higher stress levels and diastolic blood pressure over the 24-hour period with salivary cortisol levels showing a lower, flatter curve, indicating that both genders reporting marital conflict reported too higher stress throughout the day. Further, a link between problem-afflicted marriages and reduced immune functioning has been reported [26]. Other studies point to increases in psychophysiological and endocrine measures of stress, as well as changes in immune function, associated with marital conflict $[27,28]$. These reactions are generally more intensive and of longer duration in women [28]. In cases where conflict is long-lasting can even resting levels of psychophysiological measures be influenced $[29,30]$. Other studies highlight the association between problems in PR and increased risk for cardiovascular disorders [31], as well as other physiological risk factors such as blood pressure, high-density lipoprotein cholesterol levels, and body mass index [32]. Quality of PR is linked also to prognosis for myocardial infraction [31] and survival among patients with congestive heart problems [33]. PR quality is implicated too as an eventual protective factor in atherosclerosis [32], by optimising social and material resources. Finally, Troxel et al. [17]

*Corresponding author: Ann-Christine Andersson Arntén, Swedish Police Department of National Operations, Assessment Functions, 10226 Stockholm Sweden, Tel: +46-722027660; E-mail: ann.christine.andersson.arnten@psy.gu.se; acarnten@gmail.com

Received: April 15, 2018; Accepted: April 30, 2018; Published: May 07, 2018

Citation: Ann-Christine AA, Jansson B, Archer T (2018) Partner Relations and Work Stress Modulating Health Issues. Clin Exp Psychol 4: 191. doi: 10.4172/24712701.1000191

Copyright: (C) 2018 Ann-Christine AA, et al. This is an open-access article distributed under the terms of the Creative Commons Attribution License, which permits unrestricted use, distribution, and reproduction in any medium, provided the original author and source are credited. 
found that women reporting high PR quality showed a lower risk for development of metabolic syndrome.

Research concerning the psychological consequences of PR problems appears limited although there are findings pertaining to the psychobiological consequences of problems arising in PR. For example, qualitatively worse PRs are associated with a greater incidence of depressive symptoms, increased worry, etc. [34], as well as increased anxiety [32]. Concomitantly, PR defined by high levels of partner support are associated with low levels of psychological distress [35,36]. Fincham and Bradbury [37] found that high levels of depressive symptoms were contra-related to PR satisfaction while selfconfidence was positively related to PR satisfaction over both genders. After controlling for work-related stress, Blom et al. [38] showed that PR stress was linked to lower social integration, degree of experienced support, degree of belongingness and degree of actual support whereas, after controlling for PR stress, work-related stress did not exert the same influence. It has been shown that marital satisfaction was highest when both spouses experienced high work self-direction [39].

Taking into account the likelihood that poor quality of PRs is implicated in a long-lasting, elevated risk for distress underlying a wide variety of psychosomatic disorder profiles. The purpose of present study was to determine the effect of PRQ and JSS in health and in conditions of poor health. Here, health was measured by positive affect, energy, LOT and poor health by depression, anxiety, stress, psychological and somatic subjective stress experience and negative affect.

\section{Materials and Methods}

\section{Participants}

One two hundred and twelve participants (135 male and 77 female participants) equally divided between eight different occupational categories, including physiotherapists, police, sales personnel, construction foremen, teachers, administrative personnel, IT-personal and executive middle management, took part. The mean age of the whole population of participants was 39.05 years $(S D=8.93)$, with male participants aged 36.66 years $(\mathrm{SD}=6.95)$ and female participants aged 43.25 years $(\mathrm{SD}=10.40)$. A greater proportion of female participants (21.8\%) were found to be smokers compared with the male participants (13.2\%), whereas a greater proportion of male participants $(27.2 \%)$ reported that they never experience aches and pain compared with female participants $(9.0 \%)$. A greater proportion of male participants (43.4\%) also reported that they never experience sleeping problems compared with female participants (34.6\%).

\section{Design}

The study consisted of independent variables: "Work Stress (JSS divided in to: ABI, BSI and ASI)", "Partnership Relations Quality (PRQ)", and "Gender", and the dependent variables "Subjective Stress Experience; psychological and somatic", "Stress and Energy", "Anxiety" and "Depression", and "Positive and Negative affect".

\section{Instruments}

Positive affect and negative affect scale (PANAS): The PANASinstrument provides a self-estimation of "affect", both positive and negative. It consists of 10 adjectives for the NA dimension and 10 adjectives for the PA dimension. The test manual [40] postulates that the adjectives describe feelings (Affect) and mood level. Participants were instructed to estimate how they felt during the last few days. The response alternatives were presented on a five-grade scale that extended from where $1=$ not at all to $5=$ very much. For each participant the responses to the 10 negatively-charged adjectives were summated to provide a total NA-result for NA affect, and similarly the responses to the positively-adjectives were summated to provide a total PA-result for PA affect. The PANAS instrument has been validated through studies analyzing conditions associated with general aspects of psychopathology [41], as well as a multitude of other expressions of affect [42].

The participants' mean for PA was $3.70(\mathrm{SD}=0.55)$, indicating a somewhat higher value compared to the norm group ( $\mathrm{N}=6557$, $\mathrm{M}=3.35, \mathrm{SD}=0.98$. The participants' mean for NA was $1.93(\mathrm{SD}=0.59)$, indicating a somewhat lower value than that of the norm group $(\mathrm{M}=2.09, \mathrm{SD}=1.00)$.

Hospital anxiety and depression (HAD): The instrument is derived to measure depressive and anxiety symptoms [43,44]. It consists of 14 statements to which participants respond by marking one of either three or four response alternatives. For example, "I can sit still and feel relaxed" with response alternatives: Definitely, Generally, Seldom, Never, or, "I look forward with gladness towards this and that" with response alternatives: As much as before, Less than before, Hardly ever. Half of the statements were constructed to illustrate depressive symptoms whereas the other half to illustrate anxiety-related symptoms. Participants' responses thereby provided two results, one pertaining to depressive symptoms, the other to symptoms of anxiety.

Subjective stress experience (SSE): The instrument is derived from a diagnostic manual designed to assess different reactions to stress [45]. Participants were required to estimate the extent to which different statements concurred with how they felt on an ordinary working day. The first part of the instrument consisted of 23 statements wherein participants were required to respond to the extent to which they experienced, for example, "Nausea or abdominal pain" or "Overreaction to inconsequential inner stimuli/easily frightened", or, "Muscle tension", or, "Sleep problems caused by worry". The test contained statements concerning symptoms implicating autonomic activation, mood changes, tension as well as other non-specific symptoms associated with stress responses. Participants' estimations were carried out using a Visual Analogue Scale (VAS) whereby they marked a cross on a 10$\mathrm{cm}$ line ( 1 at one end and 10 at the other) whereby $1=$ "do not agree at all 2 and $10=$ agree completely". The results of the test provided a total estimation for somatic stress (SSSOM) and one for psychological stress (SSPSYK).

Partner relationship questionnaire: The questionnaire consists of 45 questions regarding individuals' partner relationships that are designed to provide a comprehensive outline of these relationships, including sexual relations. The questionnaire contains two types of scales, multiple choice alternatives and an estimation scale from 1-10. Examples of questions are, as follows: "How often do you and your partner discuss current events?" with response alternatives provided in those cases as multiple choice alternatives that vary from "Never or Almost never", "Seldom", "Sometimes", "Often", to "Very often", and "How often does petting and stroking occur between you and your partner?", with multiple choice response alternatives that vary from "Never", "Seldom", "Less than once a week", "More than once a week" to "Everyday" [46]. Examples of questions applying an estimation scale from $1-10$ are, as follows: "How much enjoyment do you get out of sexual intercourse?" whereby 1 represents "No enjoyment at all" to 10 "Very intensive enjoyment".

The estimation of "Intern partner relation" which relates to the couples experience of partnership relation quality (PRQ), was obtained from 11 of the questions from the questionnaire. Other aspects of the questionnaire were left outside the scope of the present study. 
Stress and energy (SE): The SE-instrument is a self-estimation scale that assesses individuals' experience of their own stress and energy [47]. The test is divided into two sub-scales that express each participant's level of mood in the two dimensions: "experienced stress" and "experienced energy". Response alternatives are ordered within six-graded scales that extend from $0=$ not at all to $5=$ very much. The instrument has been validated through studies concerning occupational burdens and pressures [48]. The SE-scale has been constructed from the earlier used checklist, Mood Adjective Check-List [49], which was modified by Kjellberg and Bohlin [47] and Sjöberg et al. [50]. Kjellberg and Iwanowski [48] reduced the list to 12 adjectives in the two dimensions, stress and energy, which provides the latest version applied here. Cronbach's testing indicated Alpha $=0.7644$.

The participants' mean for Energy was $3.25(\mathrm{SD}=0.83)$, indicating a somewhat higher value compared to the norm group ( $\mathrm{N}=4508, \mathrm{M}=2.93$, $\mathrm{SD}=1.94$; Karlsson and Archer, unpublished data). The participants' mean for Stress was $1.83(\mathrm{SD}=1.14)$, indicating a somewhat lower value than that of the norm group $(\mathrm{M}=2.09, \mathrm{SD}=1.94)$.

Job stress survey (JSS): The JSS instrument presents a general measure of stress at work. In the test, participants are questioned about the level of seriousness of certain stressors according to how individuals perceive them and how often these stressors have been experienced during the last six months [51]. Through the expediency of assessing the level of seriousness of the stressors as well as their frequency a distinction is made between condition and characteristic under measurement. The participants first estimate the level of seriousness of certain stressors on a 9-graded scale. Following this, they were instructed to assess on a scale from 0 to $9+$ how often each incident had occurred during the last six months. The result was tabulated on nine different scales: three of these being index scales, three grading scales and three frequency scales. These scales were separated into three different stress sources: work stress (ASI), work burden (ABI) and lack of organisational support (BSI).

Life orientation test (LOT): The LOT-instrument is a selfestimation instrument that assesses an individual's degree of dispositional optimism. The instrument is based on a general model, regarding self-regulated behaviour that indicates that optimism exerts meaningful behavioural consequences based on the model [52]. It was constructed originally to study the extent to which the personality trait optimism was associated with the ability to develop suitable 'coping strategies' in connection with severe psychological and physical handicaps (e.g. tinnitus). Since the test has been shown to be successful for predicting success-rate in physically demanding and stressful sports [53], it was considered both sufficient and necessary for inclusion in the present study. The instrument consists of 12 statements from which each participant is instructed to assess the extent to which each of these statements fits in with him/her as an individual. The response alternatives are presented on a five-graded scale extending from $0=$ "strongly disagree" to $4=$ "strongly agree". LOT is a suitable scientific instrument with an estimated internal consistency of 0.76 (Cronbach's alpha) and a Test-Retest reliability of 0.79 (Pearson's $r$ ), indicating that the test result is stable over time. The LOT test requires about 5 minutes for completion. Testing has provided separate norms for male and female participants: male participants show a mean of $21.30(\mathrm{SD}=4.56)$ and female participants $21.41(\mathrm{SD}=5.22)$. The participants' mean for LOT was $21.90(\mathrm{SD}=4.21)$, indicating a somewhat lower value compared to the norm group $(\mathrm{N}=2608, \mathrm{M}=27.30, \mathrm{SD}=3.20$; Karlsson and Archer, unpublished data). Cronbach's testing indicated Alpha $=0.6429$.

Health and background questionnaire: The questionnaire is used to assemble background data regarding health and health-related information about the participants. It consists of questions regarding gender, age, education, smoking habit, exercise, aches and pains, sleep problems, time spent watching TV, and amount of activity associated with occupation. Examples of questions include: "How often have you experienced sleep problems during the past year?" Response alternatives in this case provided for a choice between five different options including: "Constantly", "2-3 times a week", "Once a week", "Once a month", or "Never". Each participant was instructed to mark the alternative that was most appropriate for himself/herself.

\section{Procedure}

Fifteen places of work, both private and public, were contacted with regard to participation of employees in an investigation upon aspects of health. Permission to carry out the study was sought through Heads of personnel, union representatives and persons in positions of responsibility who adjudged whether or not the material could compromise the integrity of the personnel. Places of work choosing not to allow the investigation provided the following reasons: "This compromises personal integrity", "We don't have the time", and "Our policy is not to take part in any investigations". Eight places of work, representing both private and public sectors, accepted to allow the study. Nevertheless, the private sector was somewhat over-represented (68\%).

Employees at each respective place of work were informed first by their respective Heads about the study and then asked whether or not they wished to participate. All participation was on a volunteer basis and took place at the usual work place during working hours. Most of the participants were tested in groups of maximally five persons although some were tested singly. Prior to testing, participants were ensured total anonymity as well as the fact that each set of responses was unidentifiable among all the other sets of responses.

In order to avoid the possible effects of ordering of each instrument, the order in which each instrument/questionnaire occurred was randomly distributed in each envelop. Each participant picked an envelop randomly out of the box containing them. The maximum amount of time allocated for subjects to complete all the questionnaires was 30 minutes. At the start of testing, participants were informed about the purpose and background of the study and that it was above all on a volunteer basis. It was emphasis that all details of work place and personal identity were to be omitted since total anonymity was essential. On completion of all the instruments, each participant was instructed to replace all the questionnaire in the envelope. All the envelopes were collected and stored until the employees from each of the places of work had completed the tests.

\section{Results}

\section{Effect of work stress}

In order to analyse whether or not different degrees of work stress (JSS) affected the self-reported measures of health/illhealth, the individual scores on this variable were assigned to three groups on the basis of subjects' own responses to the questionnaire:- Group 1 ("Low work stress") reported low levels of stress on the JSS instrument, Group 2 ("Medium work stress") reported intermediate levels and Group 3 ("High work stress") reported high levels. Pillai's MANOVA $(3 \times 2$ factorial design) with work stress (JSS) and Gender as independent variables and with stress, energy, anxiety, depression, psychological and somatic subjective stress experience, positive and negative affect and LOT as dependent variables indicated significant main effects for 
Work stress (JSS) $[\mathrm{F}(2,193)=1.99 ; \mathrm{p}<0.05$, Eta2 $=0.09$, power $=0.98]$ and for $\operatorname{Gender}[F(1,193)=5.92 ; \mathrm{p}<0.001, \mathrm{Eta} 2=0.22$, power $=1.00]$, but no Work stress $\times$ Gender interaction effect $(\mathrm{p}=0.95)$.

One-way ANOVA with work stress (JSS) as independent variable and with stress, energy, anxiety, depression, psychological subjective stress experience och somatic subjective stress experience, dispositional optimism (LOT), Negative and Positive affect as dependent variables indicated signifikant effekts for the following variables:

Anxiety: $[\mathrm{F}(2,199)=7.30 ; \mathrm{p}<0.01, \mathrm{Eta} 2=0.06$, power $=0.84]$, whereby post hoc testing (Bonferroni's test, $5 \%$ level) indicated that the JSS "High work stress" group $(\mathrm{M}=1.04, \mathrm{SD}=0.51)$ expressed a significantly higher level of anxiety compared with the JSS "Low work stress" group $(\mathrm{M}=0.74, \mathrm{SD}=0.48)$, whereas the JSS "Medium work stress" group was intermediary $(\mathrm{M}=0.80, \mathrm{SD}=0.45)$.

Stress (SE): $[\mathrm{F}(2,199)=8.46 ; \mathrm{p}<0.001, \mathrm{Eta} 2=0.15$, power $=1.00]$, whereby post hoc testing (Bonferroni's test, $5 \%$ level) indicated that the JSS "High work stress" group $(\mathrm{M}=2.21, \mathrm{SD}=1.16)$ expressed a significantly higher level of stress compared with the JSS "Low work stress" group $(\mathrm{M}=1.44, \mathrm{SD}=1.07)$ and the JSS "Medium work stress" group $(\mathrm{M}=1.74, \mathrm{SD}=1.05)$.

Psychological subjective stress experience: $[F(2,201)=12.40$; $\mathrm{p}<0.001$, Eta2 $=0.07$, power $=0.89$ ], whereby post hoc testing (Bonferroni's test, 5\% level) indicated that the JSS "High work stress" group $(\mathrm{M}=2.80, \mathrm{SD}=1.68)$ expressed a significantly higher level of psychological subjective stress experience compared with the JSS "Low work stress" group $(\mathrm{M}=1.75, \mathrm{SD}=0.95)$ and the JSS "Medium work stress" group $(\mathrm{M}=1.94, \mathrm{SD}=1.17)$.

Somatic subjective stress experience: $[F(2,201)=7.06 ; p<0.01$, $\mathrm{Eta} 2=0.03$, power $=0.44$ ], whereby post hoc testing (Bonferroni's test, $5 \%$ level) indicated that the JSS "High work stress" group $(\mathrm{M}=2.18$, $\mathrm{SD}=1.34$ ) expressed a significantly higher level of somatic subjective stress experience compared with the JSS "Low work stress" group $(\mathrm{M}=1.54, \mathrm{SD}=0.75)$, whereas the JSS "Medium work stress" group was intermediary $(\mathrm{M}=1.64, \mathrm{SD}=1.05)$ (Table 1).

Negative affect: $[F(2,199)=8.47 ; p<0.001, E t a 2=0.07$, power $=0.87]$, whereby post hoc testing (Bonferroni, $5 \%$ level) indicated that the JSS "High work stress" group $(\mathrm{M}=2.11, \mathrm{SD}=0.58)$ and the JSS "Medium work stress" group ( $\mathrm{M}=1.70, \mathrm{SD}=0.51)$ expressed significantly higher levels of somatic subjective stress experience compared with the JSS "Low work stress" group $(\mathrm{M}=1.94, \mathrm{SD}=0.62)$. No significant effects were obtained for depression, energy (SE), or positive affect.

\section{Effect of partnership relation quality (PRQ)}

In order to analyse whether or not the different degree of work stress (JSS) affected the self-reported measures of health/illhealth, the individual scores on this variable were assigned to three groups on the basis of subjects' own responding:- Group 1 ("Low PRQ") reported low levels of PRQ, Group 2 ("Medium PRQ") reported intermediate levels and Group 3 ("High PRQ") reported high levels of PRQ.

Pillai's MANOVA $(3 \times 2$ factorial design) with PRQ and Gender as independent variables and with stress (SE), energy (SE), anxiety, depression, psychological and somatic subjective stress experience, positive and negative affekt as well as LOT as dependent variables indicated significant main effect of PRQ $[\mathrm{F}(2,172)=2.27 ; \mathrm{p}<0.01$, $\mathrm{Eta} 2=0.11$, power $=0.99]$ and $\operatorname{Gender}(\mathrm{F}(1,172)=6.40 ; \mathrm{p}<0.001, \mathrm{Eta} 2=0$. 26 , power=1.00), but no $P R Q \times$ Gender interaction effect $(p=0.97)$.

One-way ANOVA med partnership relation quality (PRQ) as the independent variables and with stress, energy, anxiety, depression, psychological subjective stress experience and somatic subjective stress experience, dispositional optimism (LOT), Negative and Positive affect as dependent variables indicated significant effects for the following variables:

Depression: $[\mathrm{F}(2,178)=9.05 ; \mathrm{p}<0.001, \mathrm{Eta} 2=0.06$, power $=0.87]$, whereby post hoc testing (Bonferroni's test, $5 \%$ level) indicated that the "High PRQ" group $(\mathrm{M}=0.39, \mathrm{SD}=0.36)$ and the "Medium PRQ" group $(\mathrm{M}=0.48, \mathrm{SD}=0.33)$ expressed significantly lower levels of depression compared with the "Low PRQ" group $(\mathrm{M}=0.66, \mathrm{SD}=0.37)$.

Anxiety: $[\mathrm{F}(2,178)=3.94 ; \mathrm{p}<0.05, \mathrm{Eta} 2=0.03$, power $=0.51]$, whereby post hoc testing (Bonferroni's test, $5 \%$ level) indicated that the "High PRQ" group ( $\mathrm{M}=1.81, \mathrm{SD}=0.84)$ expressed a significantly lower level of anxiety compared with the "Low PRQ" group $(\mathrm{M}=2.14, \mathrm{SD}=0.78)$, whereas the "Medium PRQ" group was intermediary $(\mathrm{M}=1.92$, $\mathrm{SD}=0.81$ ).

Stress (SE): $[\mathrm{F}(2,178)=5.65 ; \mathrm{p} \leq 0.01$, Eta2 $=0.06$, power $=0.80]$, whereby post hoc testing (Bonferroni's test, $5 \%$ level) indicated that the "High PRQ" group $(\mathrm{M}=1.83, \mathrm{SD}=0.79)$ expressed a significantly lower level of stress compared with the "Low PRQ" group (M=2.24, SD=0.84), whereas the "Medium PRQ" group was intermediary $(M=1.95$, $\mathrm{SD}=0.75)$.

Negative affect: $[F(2,178)=6.96 ; p \leq 0.01$, Eta2 $=0.07$, power $=0.88]$, whereby post hoc testing (Bonferroni's test, $5 \%$ level) indicated that "High PRQ" group ( $\mathrm{M}=1.75, \mathrm{SD}=0.58)$ and the "Medium PRQ" group $(\mathrm{M}=1.83, \mathrm{SD}=0.47)$ expressed a significant lower level of negative affect compared with the "Low PRQ" group $(\mathrm{M}=2.11, \mathrm{SD}=0.61)$.

No significant effects were obtained for energy (SE), psychological and somatic subjective stress experience positive affect or dispositional optimism (LOT).

\begin{tabular}{|c|c|c|c|}
\hline & $\begin{array}{l}\text { Low work stress (group 1) } \\
\qquad(n=56)\end{array}$ & $\begin{array}{l}\text { Medium work stress (group 2) } \\
\qquad(\mathrm{n}=61)\end{array}$ & $\begin{array}{l}\text { High work stress ( group 3) } \\
\qquad(\mathrm{n}=57)\end{array}$ \\
\hline Anxiety & $0.74 \pm 0.48^{*}$ & $0.80 \pm 0.45$ & $1.04 \pm 0.51$ \\
\hline Stress & $1.44 \pm 1.07^{*}$ & $1.74 \pm 1.05^{*}$ & $2.21 \pm 1.16$ \\
\hline SSPSYK & $1.75 \pm 0.95^{*}$ & $1.94 \pm 1.17^{*}$ & $2.80 \pm 1.68$ \\
\hline SSSOM & $1.54 \pm 0.75^{*}$ & $1.64 \pm 1.05$ & $2.18 \pm 1.34$ \\
\hline Negative affect & $1.70 \pm 0.51^{*}, \cdot$ & $1.94 \pm 0.62$ & $2.11 \pm 0.59$ \\
\hline Depression & $0.41 \pm 0.31$ & $0.52 \pm 0.32$ & $0.54 \pm 0.44$ \\
\hline Energy & $3.26 \pm 0.79$ & $3.29 \pm 0.84$ & $3.20 \pm 0.90$ \\
\hline LOT & $2.87 \pm 0.49$ & $2.80 \pm 0.53$ & $2.66 \pm 0.59$ \\
\hline Positive affect & $3.66 \pm 0.74$ & $3.72 \pm 0.55$ & $3.69 \pm 0.57$ \\
\hline
\end{tabular}

Note: ${ }^{*} \mathrm{p}<0.01$, versus High work stress group, Bonferroni's tests. $\bullet p<0.01$, versus Medium work stress group, Bonferroni's tests.'

Table 1: Mean ( \pm SD) scores for anxiety and depression (HAD), stress and energy (SE), psykisk och somatisk stresserfarenhet (SSE), dispositional optimism (LOT), and positive and negative affect (PANAS), by each of the three work stress groups (JSS). 


\section{Effect of gender}

One-way ANOVA with Gender as independent variable and with stress, energy, anxiety, depression, psychological subjective stress experience and somatic subjective stress experience, dispositional optimism (LOT), Negative and Positive affect as dependent variables indicated significant effects for the following variables:

Anxiety: $[\mathrm{F}(2,178)=23.03 ; \mathrm{p} \leq 0.001$, Eta2 $=0.08$, power $=0.99]$, whereby post hoc testing (Bonferroni's test, $5 \%$ level) indicated that the female participants $(\mathrm{M}=1.08, \mathrm{SD}=0.54)$ expressed a significantly higher level of anxiety compared with the male participants $(M=0.75$, $\mathrm{SD}=0.44)$.

Energy (SE): $[\mathrm{F}(1,209)=25.45 ; \mathrm{p} \leq 0.001, \mathrm{Eta} 2=0.12$, power $=1.00]$, whereby post hoc testing (Bonferroni's test, $5 \%$ level) indicated that the female participants $(M=3.61, S D=0.78)$ expressed a significantly higher level of energy compared with the male participants $(\mathrm{M}=3.04$, $\mathrm{SD}=0.79$ ).

Stress (SE): $[\mathrm{F}(1,209)=13.83 ; \mathrm{p} \leq 0.001$, Eta2 $=0.09$, power $=0.99]$, whereby post hoc testing (Bonferroni's test, $5 \%$ level) indicated that the female participants $(M=2.20, S D=1.11)$ expressed a significantly higher level of stress compared with the male participants $(\mathrm{M}=1.61, \mathrm{SD}=1.11)$.

Psychological subjective stress experience: $[\mathrm{F}(1,211)=16.93 ; \mathrm{p} \leq$ 0.001 , Eta2 $=0.04$, power $=0.83$ ], whereby post hoc testing (Bonferroni, $5 \%$ level) indicated that the female participants $(\mathrm{M}=2.71, \mathrm{SD}=1.73)$ expressed a significantly higher level of stress compared with the male participants $(\mathrm{M}=1.91, \mathrm{SD}=1.09)$.

No significant Gender effects were obtained for depression, somatic subjective stress experience, positive and negative affect or dispositional optimism (LOT) (Table 2).

\section{Regression Analysis}

Linear regression analysis was performed, applying the hierarchic method, to examine the extent to which anxiety and depression (HAD), stress and energy (SE), psychological subjective stress experience (SSPSYK) and somatic subjective stress experience (SSSOM), may be predicted from (i) work stress (JSS) and (ii) partnership relation quality (PRQ).

The analysis indicated that Depression: $[\mathrm{F}(3,172)=17.14, \mathrm{p}<0.001$, Adjusted R2=0.16], Anxiety $[\mathrm{F}(3,172)=14.56, \mathrm{p}<0.001$, Adjusted $\mathrm{R} 2=0.13]$, Stress $[\mathrm{F}(3,172)=19.05, \mathrm{p}<0.001$ Adjusted $\mathrm{R} 2=0.19]$, Psychological stress $[\mathrm{F}(3,172)=16.59 \mathrm{p}<0.001$, Adjusted $\mathrm{R} 2=0.15]$, and Somatic stress $[\mathrm{F}(3,172)=8.76 \mathrm{p}<0.001$, Adjusted $\mathrm{R} 2=0.08]$ were each predicted significantly from JSS whereas PRQ was counter-predictive for each of these five estimates of illhealth. Table 3 presents the Standardiserad $\beta$ (Standardized weights) and Standard Error for Beta (SEB) values for the linear regression analysis with depression, anxiety, energy, stress, psychological subjective stress experience and somatic subjective stress experience, respectively, as dependent variables, and (i) JSS and (ii) PRQ as independent (Predictor) variables.

Finally, each of the three work stress factors: work stress (ASI), work burden (ABI) and lack of organisational support (BSI), as well as PRQ were assigned to be independent variables with depression as dependent variable in an hierarchic regression analysis. The analysis was found to produce a significant effect: $(F(5,168)=11.32, p<0.001$, adj. R2=0.17) whereby lack of organisational support (BSI) was shown to be significantly predictive of Depression $[\beta=0.508, p<0.01]$ and PRQ was significantly counterpredictive $[-0.328, \mathrm{p}<0.01]$. Work stress (ASI) and work burden $(\mathrm{ABI})$ were not significantly predictive of depression (Table 4).

\section{Discussion}

The present findings may be summarised as follows: (1) Selfreported high levels of work stress (the JSS "High work stress" group) induced more anxiety, stress (SE), psychological and somatic subjective stress, and negative affect than self-reported low levels of work stress (the JSS "Low work stress" group), with intermediate levels of work stress (the JSS "Medium work stress" group) in between. (2) Selfreported high levels of partnership relations quality (the "High PRQ" group) was associated with less depression, anxiety, stress (SE) and negative affect than self-reported low levels of partnership relations quality (the "High PRQ" group), with intermediate levels (the "Medium PRQ" group) in between. (3) The female participants expressed more anxiety, stress (SE), energy (SE) and psychological subjective stress experience that the male participants. (4) Regression analysis indicated that depression, anxiety, stress (SE), psychological stress and somatic stress were each significantly predicted by work stress (JSS), whereas partnership relations quality was counter-predictive for depression, anxiety, stress (SE) and psychological stress.

Work-related stress is often encountered as an important factor that induces illhealth in adult as the place of work [11]. Several studies have shown that unpleasant workplace conditions have a negative influence upon employees physical and mental health $[54,55]$. The accumulated effects of high levels of chronic workplace stress, lack of recovery time, high performance requirement and psychobiological concomitants lead to serious loss of energy, exhaustion and breakdown [56]. The evidence from the present study indicates that partnership relation quality exerts a positive influence upon health and thereby ought to mediate the recovery process from sources of stress. Thus, partnership

\begin{tabular}{|c|c|c|c|}
\hline & $\begin{array}{c}\text { Low PRQ } \\
(n=55)\end{array}$ & $\begin{array}{c}\text { Medium PRQ } \\
(n=61)\end{array}$ & $\begin{array}{c}\text { High PRQ } \\
(n=58)\end{array}$ \\
\hline Depression & $0.66 \pm 0.38^{*} \bullet$ & $0.47 \pm 0.33$ & $0.38 \pm 0.36$ \\
\hline Anxiety & $1.01 \pm 0.54^{*}$ & $0.82 \pm 0.44$ & $0.77 \pm 0.48$ \\
\hline Stress & $2.15 \pm 1.22^{*}$ & $1.73 \pm 1.01^{*}$ & $1.48 \pm 1.12$ \\
\hline Negative affect & $2.11 \pm 0.61^{\star}$ & $1.83 \pm 0.47$ & $1.75 \pm 0.58$ \\
\hline Energy & $3.38 \pm 0.74$ & $3.16 \pm 0.88$ & $3.27 \pm 0.86$ \\
\hline SSPSYK & $2.42 \pm 1.51$ & $2.18 \pm 1.44$ & $1.86 \pm 1.10$ \\
\hline SSSOM & $1.89 \pm 1.26$ & $1.71 \pm 1.10$ & $1.75 \pm 1.04$ \\
\hline LOT & $2.67 \pm 0.58$ & $2.77 \pm 0.49$ & $2.87 \pm 0.53$ \\
\hline Positive affect & $3.54 \pm 0.61$ & $3.72 \pm 0.51$ & $3.78 \pm 0.55$ \\
\hline
\end{tabular}

Note: * $p<0.01$, versus High PRQ group, Bonferroni's tests. $\bullet p<0.01$, versus Medium PRQ group, Bonferroni's tests

Table 2: Means ( \pm SD) for anxiety and depression (HAD), stress and energy (SE), psykisk och somatisk subjektiv stresserfarenhet (SSE), dispositional optimism (LOT), and positive and negative affect (PANAS). by each of the three groups presenting partnership relation quality (PRQ). 
Citation: Ann-Christine AA, Jansson B, Archer T (2018) Partner Relations and Work Stress Modulating Health Issues. Clin Exp Psychol 4: 191. doi: $10.4172 / 2471-2701.1000191$

Page 6 of 8

\begin{tabular}{|c|c|c|}
\hline Predicting variables & Standardised Beta $(\beta)$ & SEB \\
\hline \multicolumn{3}{|c|}{ Depression $F(2,173)=17.14, p<0.001$, Adjusted $R^{2}=0.16$} \\
\hline JSS & $0.24^{\star \star}$ & 0.01 \\
\hline $\mathrm{PRQ}$ & $-0.32^{\star \star *}$ & 0.01 \\
\hline \multicolumn{3}{|c|}{ Anxiety $F(2,173)=14.56, p<0.001$, Adjusted $R^{2}=0.13$} \\
\hline JSS & $0.25^{* * *}$ & 0.01 \\
\hline$P R Q$ & $-0.25^{\star * *}$ & 0.01 \\
\hline \multicolumn{3}{|c|}{ Energy $F(2,174)=10.64, p<0.001$ Adjusted $R^{2}=0.14$} \\
\hline JSS & -0.08 & 0.02 \\
\hline $\mathrm{PRQ}$ & 0.02 & 0.10 \\
\hline \multicolumn{3}{|c|}{ Stress $F(2,173)=19.05, p<0.001$ Adjusted $R^{2}=0.17$} \\
\hline JSS & $0.36^{* * *}$ & 0.019 \\
\hline $\mathrm{PRQ}$ & $-0.22^{* *}$ & 0.013 \\
\hline \multicolumn{3}{|c|}{ Psychological stress $F(2,175)=16.59, p<0.001$ Adjusted $R^{2}=0.15$} \\
\hline JSS & $0.33^{* * *}$ & 0.023 \\
\hline $\mathrm{PRQ}$ & $-0.16^{*}$ & 0.015 \\
\hline \multicolumn{3}{|c|}{ Somatic stress $F(2,175)=8.76 p<0.001$ Adjusted $R^{2}=0.08$} \\
\hline JSS & $0.279^{\star \star \star}$ & 0.02 \\
\hline$P R Q$ & -0.07 & 0.30 \\
\hline
\end{tabular}

Note: ${ }^{*} p<0.05 ;{ }^{* *} p<0.01 ;{ }^{* * *} p<0.001$.

Table 3: Standardiserad $\beta$ (Standardized weights) and Std Error for Beta (SEB) values for the linear regression analysis with depression, anxiety, energy, stress, psychological subjective stress experience and somatic subjective stress experience, respectively, as dependent variables, (i) JSS and (ii) PRQ as independent variables.

\begin{tabular}{|c|c|c|c|}
\hline \multicolumn{3}{|c|}{ Work stress $\uparrow$} \\
\hline \multicolumn{3}{|c|}{ Partnership relationship $\downarrow$} \\
\hline Depression $\uparrow$ & Anxiety $\uparrow$ & Stress $\uparrow$ & Psychological stress $\uparrow$ \\
\hline
\end{tabular}

Table 4: A schematic presentation of the relationship between work stress, partnership relationship and depression, anxiety, stress, and psychologicl and somatic stress.

relation quality seems to counteract the potentially unpleasant workplace conditions and to reduce negative effects upon health due to experienced work-related stress. Regression analysis indicated that work-related stress predicted an increased risk for depression, anxiety, general stress experience and subjective somatic stress symptoms whereas high quality partnership relations predicted a reduced risk for these symptoms, thereby reinforcing the notion that good partnership conditions may counteract the negative effects of stress generated at the workplace.

Kiecolt-Glaser and Newton [28] have shown that emotional support from a partner is related to low risk for cardiovascular and other types of mortality. Levels of blood pressure are partcularly sensitive to the supportive or non-supportive relations between partners [27,57,58]. It is hypothesised that oxytocin may be the primary physiological mediator in the health-producing effects of emotional support, particularly when linked to warm and intimate caressing [59,60]. Light et al. [2] found that a higher frequency of embracing and massage from the partner was associated with a higher baseline of oxytocin levels. They found too that frequency of embracing correlated with partner-support and women reporting more frequent partner embraces showed lower baseline levels of blood pressure as well as lower heart rates during stressful conditions. A profile of more frequent partner-embracing was associated with higher baseline levels of oxytocin and lower cardiovascular response. Women presenting higher oxytocin activity showed a more effective and goal-oriented, time-limited stress response but no reduction in the peak stress response [2]. Thus, high quality partnership relations may contribute positive influences to health, and on the the other side of the coin, unhappy relations may be potential psychosocial stressors with accompanying risks for illhealth [1].

The presence of 'cross-over' effects between family-and-work and work-and-family have been investigated. Barnet et al. [25] found that partnership-related difficulties influenced biological functioning during the course of the work-day. The analysis of subjective stress indicated too that men and women expressing high levels of marital difficulty reported higher degrees of stress both during working and leisure hours which implies that dissatisfaction in partnership relations may underlie the distress contributing to elevated levels of depression and anxiety. Barnet et al. [25] showed similar results whereby poor marital quality, among middle-aged couples with long relationships, could induce chronic stress, leading to resignation and withdrawal. DeLongis et al. [61] found spousal strain interacted with spousal support to predict 'next-day' negative affect. Work-place-to-family crossover effects [62] whereby stressors from one partner's work to the other have been examined [63]. Thus, Westman and Etizion [64] found crossover effects of burnout transfered from army career officers to their wives and vice versa, whereas Demerouti et al. [56] observed crossover effects between the workplace and family among couples where both parents had occupations. Shulz et al. [65] showed the relationship between work and family whereby the negative arousal of workdays was associated more aggressive marital behaviour among women and less aggressive, but more withdrawn, marital behaviour among men. Furthermore, daily fluctuations in the workday rhythym predicted women's marital 
Citation: Ann-Christine AA, Jansson B, Archer T (2018) Partner Relations and Work Stress Modulating Health Issues. Clin Exp Psychol 4: 191. doi: 10.4172/2471-2701.1000191

Page 7 of 8

behaviour. The investigation showed too that several of these workdaymarital behaviour relationships varied as a function of the degree of marital satisfaction [65] and signal positive health prognosis [66].

\section{Conclusion}

Taken together, the present findings point towards a broad perspective, incorporating type and quality of partnership relations, for eventual treatment regimes directed at problems arising from work-related stress. Fruzzetti and Linehan [67] imply the importance and relevance of couple-related factors in assessments of individual psychopathology, and vice versa, both in disorder neurodevelopment but also in the context of relapse and recovery from distress [68]. Arkowitz-Westen and Fruzzetti [69] showed that validatory behavior predicted higher levels of satisfaction among couples in a cross-section of clinic and community populations [70].

\section{Recommendations}

The concensus of these and other findings suggest the attainment of longterm and lateral health benefits for individuals afflicted by occupational stress requires a proper understanding of partnership relations in order to reinforce the positive intervention achieved through coping strategies, cognitive and behaviour therapies

\section{Limitations}

The study sample would have benefitted from a larger sample size in order to obtain greater predictive validity.

\section{References}

1. Rook KS (1998) Investigatink the poitive and negative sides of personal relationships: through a lens darkly. In: Spitzberg BH, Cupach WR (eds.). The Dark Side of Close Relationships. Lawrence Erlbaum Associates Inc., Mahwah, NJ. pp: 369-393.

2. Light KC, Grewen KM, Amico JA (2005) More frequent partner hugs and higher oxytocin levels arbe linked to lower blood pressure and heart rate in premenopausal women. Biol Psychol 69: 5-21.

3. Whisman MA, Bruce ML (1999) Marital dissatisfaction and incidence of major depressive epiode in a community sample. J Abnorm Psychol 108: 674-678.

4. Araya R, Zitko P, Markkula N, Rai D, Jones K (2018) Determinants of access to health care for depression in 49 countries: A multilevel analysis. J Affect Disord 234: 80-88.

5. Jex SM (1998) Stress and job performance: Theory, research, and implications for managerial practice. Sage Publications, London.

6. Warr P (1999) Well-being and the workplace. In: Kahneman D, Diener E, Schwarz N (eds.). Well being: The foundations of hedonic psychology. Russell Sage Foundation, New York. pp: 392-412.

7. Cooper CL (2001) Managerial, occupational and organizational stress research. Ashgate, Hampshire, United Kingdom

8. Cooper CL, Dewe P, O'Driscoll M (2001) Organizational stress: A review and critique of theory, research and applications. Sage Publications, London.

9. Hart PM, Cooper CL (2001) Occupational stress: Toward a more integrated framework. In: Anderson AN, Ones DS, Sinangil HK, Viswesvaran C (eds.). Handbook of industrial, work and organizational psychology: Vol. 2. Organisational psychology. Sage Publications, London. pp: 93-114.

10. Kasalova P, Prasko J, Holubova M, Vrbova K, Zmeskalova D, et al. (2018) Anxiety disorders and marital satisfaction. Neuro Endocrinol Lett 38: 555-564.

11. Melamed S, Shirom A, Toker S, Berliner S, Shapira I (2006) Burnout and risk of cardiovascular disease: Evidence, possible causal paths, and promising research directions. Psychol Bull 132: 327-353.

12. Vendtgodt S (1998) Sex and quality of life in Denmark. Arch Sex Behav 27: 295-314.

13. Maslow AH (1962) Toward a psychology of being. Van Norstrand, Princeton.

14. Maslow AH (1962) Motivation \& Personality. Harper \& Row, New York.

15. Forrester NG (1980) Factors contibuting to life satisfaction of divorsed women.
Dissertation Abstract Internationel 41: 1401A.

16. Bee H (1998) Lifespan Development. Addison-Wesley, New York.

17. Troxel WM, Matthews KA, Gallo LC, Kuller LH (2005) Marital Quality and Occurrence of the Metabolic Syndrome in Women. Arch Intren Med 165: 1022 1027.

18. Wickrama KAS, Lorenz FO, Conger RD, Elder GH (1997) Marital quality and physical illness: a latent growth curve analysis. J Marriage Fam 59: 143-155

19. Berkman LF, Glass T (2000) Social integration, social networks, social support and healt. In: Berkman LF, Kawachi I (Eds.) Social Epidemiology, New York, Oxford.

20. Johanson NJ, Backlund E, Sorlie PD, Loveless CA (2000) Marital status and mortality: the national longitudinal mortality study. Ann Epidemol 10: 224-238.

21. Rook KS (1990) Social networks as a source of social control in older adults'lives. In: Giles H, Coupland N, Wieman J (eds.). Communication, health, and the elderly. University of Manchester Press, Manchester, England. pp: 4563.

22. Umberson D (1992) Gender, marital status and the social control of health behaviour. Soc Sci Med 34: 907-917.

23. Bachman HJ, Coley RL, Carrano J (2012) Low-income mothers' patterns of partnership instability and adolescents' socioemotional well-being. J Fam Psychol 26: 263-73.

24. Cortès-Franch I, Escribà-Agüir V, Benach J, Artazcoz L (2018) Employment stability and mental health in Spain: towards understanding the influence of gender and partner/marital status. BMC Public Health 18: 425

25. Barnett RC, Steptoe A, Gareis KC (2005) Marital-role quality and stress-related psychobiological indicators. Ann Behav Med 30: 36-43.

26. Kiecolt-Glaser JK, Fisher LD, Ogrocki P, Seout JC, Speicher CE, et al. (1987) Marital quality, mairtal disruption, and immune function. Psychosom Med 49:13-34.

27. Broadwell SD, Light KC (1999) Familly suppport and cardiovascular responses in married couples during conflict and other interactions. Int $\mathrm{J}$ Behav Med 6: 40-63.

28. Kiecolt-Glaser JK, Newton N (2001) Marriage and health: His and hers. Psych Bull 127: 472-503.

29. Matthews KA, Woodall KL, Allen MT (1993) Cardiovascular reactivity to stress predicts future in blood pressure. Hypertension 22: 479-485.

30. Stewart JC, France CR (2001) Cardiovascular recovery from stress predicts longitudinal changes in blood pressure. Biol Psychol 58: 105-120.

31. Orth-Gomer K, Wamala SP, Horsten M, Schenck-Gustavsson K, Schneiderman $\mathrm{N}$, et al. (2000) Marital Stress worsens prognosis in women with coronary heart disease. JAMA 284: 3008-3014.

32. Gallo LC, Troxel WM, Kuller LH, Sutton-Tyrell K, Edmundowicz D, et al. (2003) Marital status, marital quality, and atherosclerotic burden in postmenopausal women. Psychosom Med 65: 952-962.

33. Coyne JC, Rohrbaugh MJ, Shoham V, Sonnega JS, Nicklas JM, et al. (2001) Prognostic importance of marital quality for survival of congestive heart failure. Am J Cardiol 88: 526-529.

34. Balog P, Janszky I, Leinewber C, Blom M, Wamala SP, et al. (2003) Depressive symptoms inn relation to marital and work stress in women with and without coronary disease. The Stockholm Female Coronary Risk Study. J Psychosom Res 54: 113-119

35. Glenn ND, Weaver CN (1981) The contribution of marital happiness to global happiness. J Marrige Fam 43: 161-168.

36. Merikangas KR, Prusoff BA, Kupfer DJ, Frank E (1985) Marital adjustment in major depression. J Affect Disord 9: 5-11.

37. Fincham FD, Bradbury TN (1993) Marital satisfaction, depression, and attributions: A longitudinal analysis. J Pers Soc Psychol 64: 442-452.

38. Blom M, Jansky I, Balog P, Orth-Gomér K, Wamala SP (2003) Social relations in women with coronary heart disease: the effects of work and material stress. Eur J Prev Cardiol 10: 201-206.

39. Sun X, McHale SM, Crouter AC, Jones DE (2017) Longitudinal links between work experiences and marital satisfaction in african american dual-earner 
Citation: Ann-Christine AA, Jansson B, Archer T (2018) Partner Relations and Work Stress Modulating Health Issues. Clin Exp Psychol 4: 191. doi: 10.4172/2471-2701.1000191

Page 8 of 8

couples. J Fam Psychol 31: 1029-1039.

40. Watson D, Clark LA, Tellegen A (1988) Development and validation of brief measures of positive and negative affect. The PANAS scale. J Pers Soc Psychol 54: 1063-1070.

41. Huebner ES, Dew T (1995) Preliminary validation of the positive and negative affect schedule with adolescents. J Psychoeduc Assess 13: 286-293.

42. Watson D, Clark LA (1984) Negative affectivity: The disposition to experience aversive negative state. Psychol Bull 96: 465-490.

43. Zigmond AS, Smith RP (1983) The hospital anxiety and depression scale. Acta Psychiatr Scand 67: 361-370.

44. HerrmannC(1997)Internationalexperienceswith hospitalanxietyand depression scales - a review validating data and clinical results. J Psychosom Res 42 : $17-41$

45. Lópes-Ibor JJ (2002) The classification of stress related disorders in ICD-10 and DSM-IV. Psychopathology 35: 107-111.

46. Möller K (2004) The longitudinal and concurrent role of neuroticism for partner relationships. Scand J Psychol 45: 79-83.

47. Kjellberg A, Bohlin G (1974) Self-reported arousal: further development of a multi-factorial inventory. Scand J Psychol 15: 285-292.

48. Kjellberg A, Iwanowski S (1989) Stress/energiformuläret: Utveckling av en metod för skattning av sinnesstämning $i$ arbetet [Stress/energy questionnaire: development of a method for estimating mood at the workplace]. Arbetsmiljöinstitutet, Solna, Sweden.

49. Nowlis $V$ (1965) Research with the mood adjective check list. In: Tompkins SS Izard CE (eds). Affect, cognition, and personality: Empirical studies. Springer, Oxford, England.

50. Sjöberg L, Svensson E, Persson LO (1979) The measurement of mood. Scand J Psychol 20: 1-18.

51. Spielberger CD, Vagg PR (2002) Manual; JSS, job stress survey.

52. Scheier MF, Carver CS (1985) Optimism, coping, and health: assessment and implications of generalized outcome expectancies. Health Psychol 4: 219-247.

53. Norlander T, Archer T (2002) Predicting performance in ski and swim championships: effectiveness of mood, perceived exertion, and dispositional optimism. Percept Mot Skills 94: 153-164.

54. Quick JC, Tetric LE (2003) Handbook of occupational healt psychology American Psychological Association, Washington, DC.

55. Schabracq M, Winnubst J, Cooper CL (2003) The handbook of work and health psychology. Wiely, Chichester.
56. Demerouti E, Bakker AB, Shaufeli WB (2005) Spillover and crossover of exhaustion and life satisfaction among dual-earner parents. J Vocat Behav 67: 266-289.

57. Carels R, Szczepanski R, Blumenthal J, Sherwood A (1998) BP reactivity and marital stress in employed women. Psychosomatic Medicine 160: 639-643.

58. Gump B, Polk D, Kamarck T, Shiffman S (2001) Partner interactions are associated with reduced BP in the natural enviorment: ambulatory sample monitoring evidence from a healthy multiethnic adult sample. Psychosom Med 63: 423-433.

59. Insel T, Young L (2001) The neurobiology off attachment. Nat Rev Neurosci 2 129-136.

60. Moyer CA, Rounds J, Hannum JW (2004) A meta-analysis off massage therapy research. Psychol Bull 130: 3-18.

61. DeLongis A, Capreol M, Holtzmn S, O’Brien T, Campbell J (2004) Social support and social strain among husbands and wives: A multilevel analysis. J Fam Psychol 18: 470-479.

62. Brotheridge CM, Lee RT (2005) Impact of work-family interference on general well-being: A replication and extension. Int J Stress Manag 12: 203-221.

63. Crossfield S, Kinman G, Jones F (2005) Crossover of occupational stress in dual- career couples. Community, Work and Family 8: 211-232.

64. Westman M, Etizion D (1995) Crossover of stress, strain and resources from one spouse to another. J Organ Behav 16: 169-181.

65. Schulz MS, Cowan PA, Cowan CP, Brennan RT (2004) Coming home upset: Gender, marital stisfaction, and the daily spillover of workday experience into couple interactions. J Fam Psychol 18: 250-263.

66. Lwi SJ, Casey JJ, Verstaen A, Connelly DE, Merrilees J, et al. (2018) Genuine smiles by patients during marital interactions are associated with better caregiver mental health. J Gerontol B Psychol Sci Soc Sci.

67. Fruzzetti AE, Linehan MM (2004) A behavioural approach to understanding borderline personality and related disorders. Unpublished manuscript, University of Nevada, Reno. pp: 235-260.

68. Palomo T, Beninger RJ, Kostrzewa RM, Archer T (2004) Gene-environment interplay in affect and dementia: Emotional modulation of cognitive expression in personal outcome. Neurotox Res 6: 159-173.

69. Arkowitz-Weston L, Fruzzetti AE (2004) Beyond negativity: The role of acceptance and validation in predicting couple relationship quality. Unpublished manuscript, University of Nevada, Reno.

70. Kielcolt-Glaser JK, Glaser R, Cacioppo JT, MacCallum RC, Snydersmith M, et al. (1997) Marital conflict in older adults: endocrinological and immunological correlates. Psychosom Med 59: 339-349. 